\title{
Immunization Errors among Pediatrics Younger than 2 years
}

\author{
Omer Qutaiba B Al-lela ${ }^{*}$, Mohd Baidi Bahari², Sara K Baderden ${ }^{3}$, Amina Y Basher ${ }^{4}$, Hani Kareem \\ Hamoodi $^{5}$ \\ ${ }^{\text {I} C o l l e g e ~ o f ~ P h a r m a c y, ~ U n i v e r s i t y ~ o f ~ D u h o k ~(U O D), ~ D u h o k, ~ K u r d i s t a n ~ r e g i o n, ~ I R A Q . ~}$ \\ ${ }^{2}$ Faculty of Pharmacy, AIMST University, Kedah, MALAYSIA. \\ ${ }^{3}$ College of Pharmacy, University of Mustansiriya, Baghdad, IRAQ. \\ ${ }^{4}$ College of Health Sciences, University of Duhok (UOD), Duhok, Kurdistan region, \\ IRAQ. \\ ${ }^{5}$ Al-Nuaman Teaching Hospital, Baghdad, IRAQ.
}

\begin{abstract}
Received: 1 August 2017; Accepted: 25 September 2017

*Correspondence to:
\end{abstract}

Dr. Omer Qutaiba B. Al-lela, PhD, Department of Clinic Pharmacy, College of Pharmacy, University of Duhok (UOD), Duhok, IRAQ Email: omarallela@yahoo.com

Copyright: (C) the author(s),publisher and licensee Indian Academy of Pharmacists. This is an openaccess article distributed under the terms of the Creative Commons Attribution Non-Commercial License, which permits unrestricted non-commercial use, distribution, and reproduction in any medium, provided the original work is properly cited.

\begin{abstract}
Objective: This study evaluated immunization compliance, immunization completeness, and vaccination errors frequency among Iraqi pediatric. Study design this study was restricted the analysis to types of vaccines administered before 2 years of age. A cohort study of 528 pediatrics born between $1^{\text {st }}$ January 2003 and $31^{\text {st }}$ Jun 2008 was selected. Immunization history of pediatric was collected retrospectively from pediatric immunization card. Immunization doses were classified to five types: Normal dose, early dose, missed dose, late dose, and extra dose. Pediatric who received all the immunization doses without any immunization dose errors was considered as complete immunization with full compliance. If the pediatric missed at least one immunization dose, this pediatric was considered partial immunization with noncompliance, and if this pediatric received at least one immunization dose error, this pediatric was considered complete immunization with noncompliance. Results Less than half of pediatric were considered as partial immunization with noncompliance. 3696 immunization doses must receive by 528 pediatric, $25.3 \%$ of doses were normal doses, $8.3 \%$ as an early doses, $13.6 \%$ as a missed doses, $47.5 \%$ of doses were late doses, and $5.3 \%$ as an extra doses. Conclusions Immunization errors occur frequently and leading to improper immunization compliance. This study recommended increasing effort to optimize childhood immunization.
\end{abstract}

Key words: immunization, compliance, errors, pediatrics, two years.

\section{INTRODUCTION}

Immunization compliance is the best public health outcome and service indicator among population. ${ }^{[1]}$ In the last decade, the higher immunization rate among pediatric is very important public health goal to achieve highest pediatric care. The maintenance of highest immunization rate also important to decrease infection transmissions and disease control or elimination. ${ }^{[2-6]}$ Vaccines administration at an appropriate vaccination time is necessary to build immune response before pediatric being infected or exposed to vaccine's preventive infectious disease. ${ }^{[7]}$

Immunization system is a successful systematic program especially after immunization's 
development in the last century, but the immunization system is still imperfect because there are many countries have unvaccinated pediatrics. ${ }^{[6-8-26]}$

Completely immunization mean pediatrics received all the scheduled vaccines without any missed immunization dose, while partial immunization mean pediatrics missed one or more of vaccination doses. But if the pediatric did not receive any immunization dose during his life that is considered as non-immunized pediatric. ${ }^{[1]}$ Pediatric with full immunization compliance mean receive complete immunization, but pediatric who have complete immunization is not necessarily full immunization compliance because they may be received all vaccines but not at appropriate vaccination time and this is attributed to improper immunization practice in the health institutions. ${ }^{[27-28]}$

Immunization compliance measurements depend on the immunization error types throughout the vaccination period. In the previous study, pediatric immunization errors classified to five error types depend on the "five right" framework, that error types are wrong vaccine, wrong time, wrong dose, wrong route, and wrong patients. ${ }^{[2]]}$ In other studies, immunization compliance measurement correlate to schedule time errors, it is classified to three types; missed opportunity (late dose or missed dose), extra immunization dose, and invalid immunization dose ${ }^{[4-30-35]}$

\section{METHODS}

Data source: An observational retrospective cohort study design where the data was collected among pediatrics born between $1^{\text {st }}$ January 2003 and $31^{\text {st }}$ Jun 2008 and younger than 2 years visited public health clinics in Iraq. Five different health clinics were selected in the Mosul city- Iraq. Each child has an immunization card to record the detail of the immunization received. The data from the immunization card was extracted retrospectively to obtain the immunization history of each individual child.

Research approval: The approval was obtained from the ministry of health-Iraq. The parents and clinic staffs were informed about the study aims and other details. If the parents agreed to participate, they were asked to sign the consent form before the data collection.

Data collection form: This study collected data from two important sources; the pediatric immunization card and the parents. The first part consist of demographic data include age, gender, race, weight at birth, and nutrition history. Age variable as a continuous variable was messuared by month. Pediatric gender classified to male and female, race classified to Arabic and Kurdish, and pediatric weight at birth classified to pediatric $<2500 \mathrm{gm}$ and pediatric $\geq 2500 \mathrm{gm}$. Nutrition history include the type of milk during lactation period, and classified to four groups: breast feeding, artificial feeding, bottle feeding-normal milk, and bottle feeding-medical milk.

The second part was the immunization schedule for pediatric. This part consists of immunization history of each individual child. This study was restricted the analyses to the following types of vaccines administered before age 2 years: Bacille Calmette-Guérin (BCG) vaccine, oral polio vaccine (OPV), diphtheria-tetanus-pertussis (DTP) vaccine, hepatitis $B$ virus (HBV) vaccine, measles-mumpsrubella (MMR) vaccine, and Measles vaccine. As shown in Table 1, a child was consider up to date if the following immunizations were received by age 2 years: one BCG dose, 5 or 4 polio vaccine doses (OPV), 4 DTP vaccine doses, $3 \mathrm{HBV}$ vaccine doses, and $1 \mathrm{MMR}$ vaccine dose. According to world health organization in Iraq, each pediatric must be received seven doses at seven time, every dose consist of many type of vaccine. The first dose at birth consists of BCG, OPV, and HBV, the $2^{\text {nd }}$ dose at two months of age consist of OPV, HBV, and DTP, the $3^{\text {rd }}$ dose at four months of age consist of OPV and DTP, the $4^{\text {th }}$ dose at six months of age consist of OPV, HBV, and DTP. Measles is the $5^{\text {th }}$ dose of immunization which received at nine months of age; while MMR is the $6^{\text {th }}$ dose of immunization at 15 months of age, and the last dose was received at 18 months consist of OPV, and DTP.

Immunization doses and status definitions: This study adapted the definition by the Advisory Committee in Immunization Practice (ACIP) recommendation, which defined the appropriate scheduling of immunizations and minimal ages. Immunization doses were classified into five types. Immunization doses were considered normal immunization doses if they were administered at the recommended age. Immunization doses were considered early immunization doses if they were administered before the recommended age (Early but valid) or before the minimal interval between-doses and must be repeated (Early and invalid).

Missed immunization doses is defined as pediatric didn't receive at least one immunization dose, while a late immunization doses is defined as the immunization dose given later than the recommended age for that dose in the series.

Children who received more than the recommended number of doses of any vaccine before age 2 years will be 


\begin{tabular}{|c|c|c|c|c|c|c|c|}
\hline \multirow[t]{2}{*}{ Vaccine type } & \multicolumn{7}{|c|}{ Age (months) } \\
\hline & At birth & $\begin{array}{l}\text { Two } \\
\text { months }\end{array}$ & $\begin{array}{l}\text { Four } \\
\text { months }\end{array}$ & Six months & $\begin{array}{l}\text { Nine } \\
\text { months }\end{array}$ & $\begin{array}{l}\text { Fifteen } \\
\text { months }\end{array}$ & $\begin{array}{l}\text { Eighteen } \\
\text { months }\end{array}$ \\
\hline BCG & $1^{\text {st }}$ & & & & & & \\
\hline HBV & $1^{\text {st }}$ & $2^{\text {nd }}$ & & $3^{\text {rd }}$ & & & \\
\hline DTP & & $1^{\text {st }}$ & $2^{\text {nd }}$ & $3^{\text {rd }}$ & & & $4^{\text {th }}$ \\
\hline OPV & $1^{\text {st }}$ & $2^{\text {nd }}$ & $3^{\text {rd }}$ & $4^{\text {th }}$ & & & $5^{\text {th }}$ \\
\hline MMR & & & & & & $1^{\text {st }}$ & \\
\hline Measles & & & & & $1^{\text {st }}$ & & \\
\hline
\end{tabular}

\begin{tabular}{ll}
\hline \multicolumn{2}{l}{ Table 2: Demographic data of Pediatric } \\
\hline Variables & N (\%) \\
\hline Weight at birth & $261(49.4)$ \\
$\geq 2500 \mathrm{gm}$ & $267(50.6)$ \\
$<2500 \mathrm{gm}$ & \\
Gender & $261(49.4)$ \\
Male & $267(50.6)$ \\
Female & \\
Race & $512(97.0)$ \\
Arabic & $16(3.0)$ \\
Kurdish & \\
Nutrition history & $290(54.9)$ \\
Breast feeding & $98(18.6)$ \\
Artificial feeding & $110(20.8)$ \\
Bottle feeding- Normal milk & $30(5.7)$ \\
Bottle feeding- Medical milk &
\end{tabular}

Table 3: Immunization completeness and compliance

\begin{tabular}{ll} 
Variables & N (\%) \\
\hline Complete immunization with full compliance & $4(0.7)$ \\
Complete immunization with noncompliance & \\
& $282(53.5)$ \\
Partial immunization with noncompliance & 242(45.8) \\
\hline
\end{tabular}

considered Extra immunization doses. Extra-immunization doses were categorized as either superfluous (administered before age 2 years after completion of the initial series) or make-up (to compensate for a prior early and invalid immunization). If a make-up immunization was given, and then only 1 dose error will count (for the early and invalid immunization).

When the pediatric received all the immunization doses without any immunization dose errors, this child is considered as complete immunization with full compliance, while if the pediatric missed at least one immunization dose, this pediatric was considered partial immunization with noncompliance, where as if this pediatric received at least one immunization dose error, this pediatric is considered complete immunization with noncompliance.

Statistical Analysis: Data was analyzed by using computer programs SPSS for windows (Statistical Package for Social Science) version 15.0. Descriptive statistics were used for the distribution of the pediatric demographic data and immunization status. Percentages and frequencies were used for the categorical variables, while mean and standard deviations were calculated for the normally distributed continuous variables and mean with median were calculated for the non-normally distributed continuous variables.

\section{RESULTS}

The average age of the pediatric was 43.29 months $(\mathrm{SD}=23.2)$, with a minimum and maximum age of 18,95 months respectively. Pediatric weights at delivery and gender distribution of the pediatric were approximately equal. The percent of Arabic pediatric was higher than Kurdish pediatric. More than half of the pediatrics were on breast feeding. Table (2) shows the demographic characteristics of the pediatrics. Only 4 pediatrics have received all vaccines in the appropriate time and consider as complete immunization with full compliance. While two hundred eighty two pediatric were immunized with all vaccination doses but not all at the appropriate time and considered as complete immunization with noncompliance, but less than half of pediatric had one or more than one missed dose and it is the partial immunization with noncompliance. Table (3) shows the resulted frequency and percentage of immunization completeness and compliance types.

Five hundred and twenty eight pediatrics received 3696 $(100 \%)$ vaccination dose. Most of this vaccination doses were given as a late dose $(47.5 \%)$. The majority of normal doses were shown in the first dose at first week of pediatric 


\begin{tabular}{|c|c|c|c|c|c|c|}
\hline \multirow[t]{2}{*}{ Pediatric age (dose) } & \multicolumn{6}{|c|}{ Dose frequency (\%) } \\
\hline & Normal dose & $\begin{array}{l}\text { Early dose } \\
\text { (invalid) }\end{array}$ & $\begin{array}{l}\text { Missed } \\
\text { dose }\end{array}$ & Late dose & Extra dose & Total \\
\hline First week (first dose) & $238(45.1)$ & $0(0)$ & $12(2.3)$ & $243(46.0)$ & $35(6.6)$ & $528(100)$ \\
\hline 2 months ( $2^{\text {nd }}$ dose $)$ & $168(31.8)$ & $10(1.9)$ & $14(2.7)$ & $330(62.5)$ & $6(1.1)$ & $528(100)$ \\
\hline 4 months ( $3^{\text {rd }}$ dose $)$ & $154(29.1)$ & $10(1.9)$ & $30(5.7)$ & $333(63.1)$ & $1(0.2)$ & $528(100)$ \\
\hline 6 months ( $4^{\text {th }}$ dose $)$ & $142(26.7)$ & $38(7.4)$ & $55(10.4)$ & $285(54.0)$ & $8(1.5)$ & $528(100)$ \\
\hline 9 months ( $5^{\text {th }}$ dose $)$ & $112(21.2)$ & $55(10.4)$ & 104(19.7) & $220(41.7)$ & $37(7.0)$ & $528(100)$ \\
\hline 15 months $\left(6^{\text {th }}\right.$ dose $)$ & $74(14.0)$ & $72(13.4)$ & $131(24.8)$ & $171(32.6)$ & $80(15.2)$ & $528(100)$ \\
\hline 18 months $\left(7^{\text {th }}\right.$ dose $)$ & $51(9.7)$ & $113(21.4)$ & $159(30.1)$ & $177(33.5)$ & $28(5.3)$ & $528(100)$ \\
\hline Total & $939(25.3)$ & $307(8.3)$ & $505(13.6)$ & $1759(47.5)$ & 195(5.3) & $3696(100 \%)$ \\
\hline
\end{tabular}

\begin{tabular}{|c|c|c|c|c|c|c|c|c|c|c|}
\hline \multirow{3}{*}{$\begin{array}{l}\begin{array}{l}\text { Number } \\
\text { of doses }\end{array} \\
\text { No dose }\end{array}$} & \multicolumn{10}{|c|}{ Number of pediatric receive (\%) } \\
\hline & \multicolumn{2}{|c|}{ Normal dose } & \multicolumn{2}{|c|}{ Early dose } & \multicolumn{2}{|c|}{ Missed dose } & \multicolumn{2}{|c|}{ Late dose } & \multicolumn{2}{|c|}{ Extra dose } \\
\hline & 132 & 25.0 & 285 & 54.0 & 292 & 54.1 & 292 & 54.1 & 360 & 68.2 \\
\hline 1 dose & 150 & 28.4 & 195 & 36.9 & 108 & 20.7 & 108 & 20.7 & 141 & 26.7 \\
\hline 2 doses & 84 & 15.9 & 46 & 8.7 & 55 & 10.5 & 55 & 10.5 & 27 & 5.1 \\
\hline 3 doses & 79 & 15.0 & - & - & 38 & 7.4 & 38 & 7.4 & - & - \\
\hline 4 doses & 49 & 9.3 & - & - & 21 & 4.0 & 21 & 4.0 & - & - \\
\hline 5 doses & 20 & 3.8 & 1 & 0.2 & 13 & 2.5 & 13 & 2.5 & - & - \\
\hline 6 doses & 10 & 1.9 & 1 & 0.2 & 4 & 0.8 & 4 & 0.8 & - & - \\
\hline 7 doses & 4 & 0.8 & - & - & - & - & 292 & 54.1 & - & - \\
\hline
\end{tabular}

life, but the majority of the early and missed doses were found in the last immunization dose at $18^{\text {th }}$ months of age. More than 330 late doses were shown in $3^{\text {rd }}$ dose of immunization schedule and 80 doses as extra dose were found in $6^{\text {th }}$ dose at 15 month of pediatric age. Table (4) shows the frequency and percentage of immunization dose types.

More than $28 \%$ of pediatrics were immunized with one normal immunization dose out of seven immunization doses, but only four pediatrics were immunized with seven normal immunization doses. Table (5) shows the number of normal immunization dose received by pediatric during immunization schedule. More than half of pediatrics were immunized without any early immunization dose out of seven immunization doses, but $0.2 \%$ of pediatrics were immunized with 6 early immunization doses. Table (5) shows the number of early immunization dose received by pediatric during immunization schedule. More than $50 \%$ of pediatrics were immunized without any missed immunization dose out of seven immunization doses, but four of them missed six immunization doses. Table (5) shows the number of immunization dose missed by pediatric during immunization schedule. There were 145 pediatrics received four late immunization dose out of seven immunization doses, and $1.5 \%$ of pediatrics were immunized with 7 late immunization doses. Table (5) shows the number of late immunization dose received by pediatric during immunization schedule. Majority (68.2\%) of pediatric were immunized without any extra immunization dose out of seven immunization doses, and $5.1 \%$ of pediatric were immunized with two extra immunization doses. Table (5) shows the number of extra immunization dose received by pediatric during immunization schedule.

\section{DISCUSSION}

Compliance measurement of vaccination is one of the important components to evaluate the pediatric health care. Pediatric who have full immunization compliance means that the pediatric have received a high level of health care provided by parents and immunization providers.

In Iraq, immunization programs have significantly improved public's health care by limiting or decreasing the 
spread of infection. Although Iraq immunization system has successfully increase the vaccination rate in pediatric younger than 2 years, most of Iraqi pediatrics still do not receive all the scheduled vaccine doses. Mosul is a second largest town after the capital city (Baghdad). According to the report of health directory of Mosul in 2008, about 116,076-pediatrics need to be vaccinated with all vaccines listed in immunization schedule. In the same report, it was indicated that the first dose of hepatitis B virus vaccine (HBV) had a highest percent $(99.71 \%$ ), while the third dose of same vaccine (HBV) had a lowest percent $(74.8 \%)$ among all vaccines received by the pediatrics.

In the current study approximately $45 \%$ of pediatrics was not up-to-date to immunization schedule, the partial and noncompliance to immunization may be related to the lack of provider's and parent's immunization knowledge, lack of vaccine availability, and lack of funding and incentives. Provider's knowledge about vaccine's contraindication is very important because some physicians postponed the vaccination time because the pediatrics have mild or low grade fever. Parent's knowledge related to vaccine's adverse effect may reduce parent's wariness about infection secondary to vaccination. Lack of vaccine availability is the important barriers in Iraq especially after United Nations (UN) sanctions in 1991 and after coalition forces invasion in 2003 . More than $50 \%$ of pediatrics completed the vaccination schedule but without immunization compliance. The percentage of pediatrics immunization is not a good health care indicators in Iraq because the pediatric immunization is mandatory and pediatrics must received all the important vaccines before they are allowed to register to kindergarten or school at three to six year of age.

Immunization compliance reflect the real pediatric health care picture, and the dose errors counting are important method to measure immunization compliance. This study observed a high frequency of immunization dose or time errors and consistent with previous studies. Many studies showed that $8-35 \%$ of children received invalid immunization doses. ${ }^{[30,32]}$ The financial factor has the important impact on immunization. A study in USA analyzed the frequency of invalid doses and found that $10.5 \%$ of children received at least one invalid doses, which resulted in excess annual costs of $\$ 10$ million. ${ }^{[7]}$ Other study analyzed the frequency of extra-immunization doses among US children and found that $21 \%$ of children received extraimmunization doses, which resulted in excess annual costs of $\$ 26.5$ million. ${ }^{[4]}$ Finally, immunization compliance levels could be increased up to $30 \%$ by avoiding missed and late immunization doses.
In this study, approximately $28 \%$ of pediatric received only one normal immunization dose at appropriate time. The first immunization dose (BCG+HBV+OPV) have a highest percent as a normal immunization dose. The highest percent of this dose may be related to the vaccination schedule for pediatric which require the first vaccine to be given at the first three days of live while mother and her child still in the hospital and this first dose was not need to vaccination reminder. The normal immunization dose is inversely proportional to pediatric age, meaning that the number of normal immunization dose decrease with increasing in pediatric age. This decrease in the normal doses my related to the decreasing in parent care for pediatric with increase in age. Early immunization doses were less frequently administered to pediatric and more than $50 \%$ of pediatrics were vaccinated without any early immunization doses. If immunization dose was administered before pediatric reach the minimal age of vaccination, the dose was considered as invalid dose and must be repeated. As a result, it will lead to extraimmunization dose. However, we consider the pediatric with under immunization if this dose were not repeated or substituted by other dose. Sometime this type of dose was administered before vaccination time but it is still a valid dose and do not need to repeat because it was administered at appropriate interval between doses. ${ }^{[7]}$ Determination process of the maximum and minimum interval period between doses is difficult and differs between different vaccinations. At 2005, WHO recommend that exclude the invalid dose from any immunization coverage estimation. Consequently, there are many study in United State of America (USA) have evaluated immunization compliance and excluded the invalid doses. ${ }^{[7-31-32-34]}$

Immunization completeness and compliance are highly affected by missed immunization doses. This dose will change the immunization status of pediatric from complete immunization to partial immunization. As shown in Table 4, the missed immunization doses have a direct proportion with pediatric age. In Table 5, approximately 300 pediatrics out of 528 pediatrics did not missed any immunization dose and this related to the immunization program in Iraq is mandatory and free administered to pediatric.

According to late immunization dose and extra immunization dose, more than a quarter of pediatrics received four late immunization doses and approximately 140 pediatrics received one extra-immunization doses. Most of these doses followed or cover the missed opportunity of immunization. That mean the parent have enough knowledge about vaccination benefits but not know the importance of appropriate time of vaccination. This 
study considered the late and extra-immunization doses as immunization dose or time error. ${ }^{[4]}$ However, these errors will increase the immunization completeness but will not increase immunization compliance because the late dose and extra dose will make-up the greatest dose errors missed dose and invalid dose, respectively. ${ }^{[4]}$

Recommendation: We recommend the following activities to improve immunization compliance and completeness by reducing vaccination dose and time errors:

1. Increase parent knowledge about vaccine benefits and risk through clinics workshop at weekend to decrease parent wariness from vaccine side effect.

2. Increase physician or vaccine provider's knowledge about contraindication to reduce missed opportunity of pediatric immunization.

3. Remind the parent for the next vaccination visit by recall notices or mobile SMS.

4. Physician reminder in electronic form for vaccine needed during pediatric visit.

5. Repeated measurement and evaluation of immunization compliance to protect pediatrics from errors.

Limitation: There was one major limitation to this study. A clustering and convenience sample of Mosul pediatric and parents was used and the results of this study could only be generalized to the City of Mosul.

\section{CONFLICT OF INTEREST}

The authors declare that they have no conflict of interest.

Funding: None

\section{ACKNOWLEDGMENT}

I would like to acknowledge the institute of postgraduate's studies, Universiti Sains Malaysia "USM" for their support in achieving this work through the USM fellowship program.

\section{Abbreviations: None}

\section{REFERENCES}

1. Nath B, Singh J, Awasthi S, Bhushan V, Kumar V, Singh S. KAP Study on Immunization of Children in a City of North India-A 30 Cluster Survey. J Health Allied Sci. 2008;7(1):1-6.
2. Centers for Disease Control and Prevention (CDC). Status report on the Childhood Immunization Initiative: reported cases of selected vaccinepreventable diseases--United States, 1996. MMWR Morbidity Mortal Weekly Rep. 1997;46(29):665-71.

3. Centers for Disease Control and Prevention (CDC). Ten great public health achievements--United States, 1900-1999. MMWR Morbidity Mortal Weekly Rep. 1999;48(12):241-3.

4. Feikema S, Klevens R, Washington M, Barker L. Extra immunization among US children. J Am Med Assoc. 2000;283(10):1311-7.

5. Lutwick S. Pediatric vaccine compliance. Pediatric Clinical North Am. 2000;47(2):427-34.

6. Duclos P. Vaccination coverage of 2-year-old children and immunization practices--Canada, 1994. Vaccine. 1997;15(1):20-4.

7. Stokley S, Maurice E, Smith P, Klevens R. Evaluation of invalid vaccine doses. Am J Prev Med. 2004;26:34-40.

8. Al-lela O, Bahari M, Alabbassi M, Basher A. Right Immunization Doses Received by Pediatric Younger than 2 Years. Value in Health. 2011;14(3):A120-A.

9. Al-lela O, Bahari M, Alabbassi M, Basher A. How Many Immunization does were missed in Pediatrics Younger than 2 years? Value in Health. 2011;14(3):120-A.

10. Al-lela O, Bahari M, Alabbassi M, Basher A. Immunization Barriers and Suggested Solutions in Iraq. Value in Health. 2011;14(3):A120-A1.

11. Al-lela O, Bahari M, Alabbassi M, Saleh M, Basher A, Shafie A. PIN88 Late Immunization Doses Received by Children Younger than Two Years. Value in Health. 2011;14(7):A281.

12. Al-lela O, Bahari M, Alabbassi M, Salih M, Basher A. PIH4 Immunization Status and Families' Factors in Iraq. Value in Health. 2012;15(7):A638.

13. Al-Lela O, Bahari M, Alabbassi M, Salih M, Basher A. PIH9 Association Between Health Care Providers and Immunization Compliance in Iraq. Value in Health. 2012;15(7):A639.

14. Al-Lela O, Bahari M, Al-Abbassi M, Salih M, Basher A. Iraqi parents' views of barriers to childhood immunization. EMHJ. 2013;19:295-7.

15. Al-Lela OQ, Bahari MB, Al-Abbassi MG, Salih MR, Basher AY. Estimation of immunization providers' activities cost, medication cost, and immunization dose errors cost in Iraq. Vaccine. 2012;30(26):3862-6.

16. Al-lela $O Q$, Bahari MB, Al-abbassi MG, Salih MR, Basher AY. Influence of health providers on pediatrics' immunization rate. J Tropical Pediatrice. 2012;58(6):441-5.

17. Al-lela $O Q$, Bahari MB, Salih MR, Al-abbassi MG, Elkalmi RM, Jamshed SQ. Factors underlying inadequate parents' awareness regarding pediatrics immunization: findings of cross-sectional study in Mosul-Iraq. Bio Med Central Pediatrics. 2014;14(1):29.

18. Al-lela OQB, Bahari MB, Al-abbassi MG, Basher AY. Development of a questionnaire on knowledge, attitude and practice about immunization among Iraqi parents. J Public Health. 2011;19(6):1-7.

19. Al-lela OQB, Bahari MB, Al-Qazaz HK, Salih MR, Jamshed SQ, Elkalmi RM. Are parents' knowledge and practice regarding immunization related to pediatrics' immunization compliance? a mixed method study. Bio Med Central Pediatrics. 2014;14(1):20.

20. Awadh AI, Hassali MA, Al-lela OQ, Bux SH, Elkalmi RM, Hadi H. Immunization knowledge and practice among Malaysian parents: a questionnaire development and pilot-testing. Bio Med Central Public Health. 2014;14(1):1107.

21. Awadh Al, Hassali MA, Al-Lela OQ, Bux SH, Elkalmi RM, Hadi H. Does an educational intervention improve parents' knowledge about immunization? Experience from Malaysia. Bio Med Central Pediatrics. 2014;14(1):254.

22. US Department of Health Human Services. Healthy people 2010: Understanding and improving health: US Government Printing Office Washington, DC; 2000.

23. Der-Wal M, Diepenmaat A, Pel J, Hirasing R. Vaccination rates in a multicultural population. Archives of disease in childhood. 2005;90(1):36-40.

24. Tozzi A. Field evaluation of vaccine safety. Vaccine. 2004;22(15):2091-5.

25. Lopreiato J, Ottolini M. Assessment of immunization compliance among children in the Department of Defense health care system. Pediatrics. 1996;97(3):308-11.

26. Richards A, Sheridan J. Reasons for delayed compliance with the childhood 
vaccination schedule and some failings of computerized vaccination registers. Australian and New Zealand J Public Health. 1999;23(3):315-7.

27. Kenyon TA, Izurieta $\mathrm{H}$, Shulman ST, et al. Large outbreak of pertussis among young children in Chicago, 1993: investigation of potential contributing factors and estimation of vaccine effectiveness. Pediatric Infectious Disease J. 1996;15(8):655-61.

28. The National Vaccine Advisory Committee. The measles epidemic. The problems, barriers, and recommendations. J Am Med Assoc. 1991;266(11):1547-52.

29. Bundy D, Shore A, Morlock L, Miller M. Pediatric vaccination errors: Application of the " 5 rights" framework to a national error reporting database. Vaccine. 2009;27(29):3890-6.

30. Luman E, McCauley M, Stokley S, Chu S, Pickering L. Timeliness of childhood immunizations. Pediatrics. 2002;110(5):935-9.

31. Hamlin J, Wood D, Pereyra M, Grabowsky M. Inappropriately timed immunizations: types, causes, and their relationship to record keeping. Am J Public Health. 1996;86(12):1812-4.

32. Butte A, Shaw J, Bernstein $\mathrm{H}$. Strict interpretation of vaccination guidelines with computerized algorithms and improper timing of administered doses. The Pediatric Infectious Dis J. 2001;20(6):561-5.

33. Mell LK, Davis RL, Mullooly JP. Polio extra immunization in children younger than 2 years after changes in immunization recommendations. Pediatrics. 2003;111(12):296-301.

34. Vivier P, Alario A, Simon P, Flanagan P, O'haire C, Peter G. Immunization status of children enrolled in a hospital-based Medicaid managed care practice: the importance of the timing of vaccine administration. Pediatric Infectious Disease J. 1999;18(9):783-8.

35. Vivier P, Alario A, Peter G, Leddy T, Simon P, Mor V. An analysis of the immunization status of preschool children enrolled in a statewide Medicaid managed care program. The J Pediatrics. 2001;139(5):624-9.

Cite this article as: Al-lela OQB, Bahari MB, Basher AY. Immunization Errors among Pediatrics Younger than 2 years. J Pharm Pract Community Med. 2017;3(4):267-73. 